\title{
Dyspeptic Syndrome And Infection By Helicobacter Pylori Exhibit Histopathologic Correlation When Observed In Adolescents
}

Jorge André Cartaxo Peixoto1, Jucier Gonçalves Júnior ${ }^{2}$, Fernando Luiz Afonso Fonseca1, David Feder ${ }^{1}$

\section{Abstract}

Objective: Chronic gastritis is a histological entity and is primarily associated with Helicobacter pylori infection. The main reason for controversy is the lack of correlation between dyspeptic symptoms and histopathologic changes. The purpose of this study was to compare histological findings with dyspeptic symptoms in adolescents.

Methods: Adolescents aged 10 to 19 years old with dyspeptic symptoms were referred to upper endoscopy. A protocol was systematically submitted to all patients prior to endoscopy. Histopathologic examination was performed on biopsy specimens. H. pylori infection was detected by rapid urease test and histology.

Results: A total of 162 consecutive outpatients with dyspeptic complaints and indication for endoscopy were entered in the database of this study. The mean age of the sample was 16 years old; There were 120 females (74\%) and 42 males (26\%). Helicobacter pylori were present in 123 patients (75.9\%) with a Pearson's coefficient of 0.7 (infection versus symptoms). The frequency of gastritis in the antrum and incisura angularis was significantly higher in subjects who had epigastric pain $(p=0,004)$. Superficial gastritis was 2 times more frequent among subjects who had epigastric pain than those who do not presented $(p=0,012)$. Severe gastritis was significantly more frequent among those who had epigastric pain $(p=0,016)$. There was no correlation between gastritis and other dyspeptic symptoms.
1 Faculty of Medicine, Postgraduate Program in Health Sciences, FMABC, Santo André, São Paulo, Brazil.

2 Faculty of Medicine, Federal University of Cariri, UFCA, Barbalha, Ceará, Brazil.

Contact information:

Jucier Gonçalves Júnior.

Tel: (055) (88)99176746

Address: 284, Divine Savior Street, Downtown, Barbalha, Ceará, Brazil, 63180000

” juciergjunior@hotmail.com 
Conclusion: This study shows that there is a correlation between epigastric pain and superficial gastritis of greater intensity and infection by $H$. pylori. There is no correlation between epigastric pain and intestinal metaplasia in adolescents. Gastritis of the antrum and incisura angularis showed a correlation to regurgitation. Gastritis was not associated to other dyspeptic symptoms

\section{Keywords}

Adolescents; dispeptic symptoms; Helicobacer pylori; histopathologic findings

\section{Introduction}

Gastritis is common disorders that affect dyspeptic patients. The definitions of gastritis are based on morphological data. It represents a heterogeneous group of macroscopic and microscopic changes of gastric mucosa resulting from injury of varied origin, usually associated with an acute or chronic inflammatory response. The term gastritis is used not only by laymen but also by many physicians as synonymous with dyspepsia, and by endoscopists to describe macroscopic changes of gastric mucosa, with almost no significance as an indicator of histologic evidence of gastritis. The main reason for controversy is the lack of correlation between the clinical and endoscopic and histopathologic changes. A wide variety of environmental agents, chemicals and infectious, can damage the stomach lining, causing a number of diseases, acute and chronic, specific and nonspecific, encompassed under the title of gastritis [1]. The designation of gastritis should be restricted to cases where besides cell damage and regenerative process, there is infiltration of inflammatory mucosa, occasionally with the presence of lymphoid follicles, especially being related to infection by Helicobacter pylori (Hp). Histologic examination of gastric mucosal biopsies is necessary to establish diagnosis of gastritis. In clinical practice, the role of the pathologist who evaluates a gastric biopsy for gastritis is to find the cause of gastritis because that will provide direct targets toward which therapeutic measures can be directed [2].
The chronic gastritis is a histological entity and is primarily associated with Helicobacter pylori infection $[3,4]$. Chronic gastritis is characterized by a chronic inflammatory cell infiltrate located mainly in the corium of the gastric mucosa, but sometimes also in the submucosa, consisting mainly of lymphocytes and plasma cells. The chronic inflammatory process affects the stomach and causes progressive destruction of glandular structures in some cases favoring the development of gastric atrophy [5]. The main feature is diffuse and superficial involvement of antrum location. The micronodular aspect observed in the beard of antrum mucosa is quite specific but has low sensitivity. The erythema observed in the antrum and the presence of erosions are often described in chronic gastritis associated with Helicobacter pylori infection, as well as areas of edema, subtle changes in mucosal folds and opalescence "pearl" of the mucosa.

The infection by Helicobacter pylori is considered a risk factor for type I carcinogenesis; also cited as the main cause of antral gastritis, is credited as a co-environmental factor in gastric carcinogenesis. Some more virulent $H$. pylori strains produce a protein encoded by the cytotoxin-associated gene (cag A). Infection by certain strains associated with this cytotoxin present a greater relationship with epithelial cell damage and cytotoxicity, with production of IL-8 pro-inflammatory. However, the influence of the conditions of the cag $A$ in the development of gastric cancer is unclear, but there's hypothesis by this event. The appearance of gastric carcinoma is related to the sequential progression of chronic 
gastritis to atrophic gastritis, intestinal metaplasia (IM), dysplasia and finally carcinoma. This sequence of gastric carcinogenesis, also called "Correa's Cascade" was initiated by Helicobacter pylori infection. The development of dysplasia from normal muco$\mathrm{sa}$ is a result of complex phenomena that occur through atrophy and metaplasia. The phenomena best known are: the loss of DNA repair capacity, increased endothelial cell proliferation, free radicals of oxygen, and the presence of nitrosamines, nitric oxide and bacterial products, including toxins.

Helicobacter pylori infection is associated with an increased risk of gastric cancer, although the risk is greatest in the subgroup of patients who have extensive atrophic gastritis and intestinal metaplasia (IM). Helicobacter pylori act as a trigger sequence that begins with atrophic gastritis and progresses to immature forms of intestinal metaplasia and dysplasia. Preliminary data suggest that eradication of Helicobacter pylori does not reverse intestinal metaplasia and moderate-to-severe atrophy rarely regresses [6]. However, it is possible that eradication could prevent progression to immature forms of intestinal metaplasia and dysplasia. It should be emphasized that $\mathrm{Hp}$ infection is not the only cause of IM. In terms of histological changes IM may represent the "point of no return" [7].

In general, children experience less inflammation than adults. Adolescence is an intermediate period between childhood and adulthood. This fact generates questions that emphasize the need for studying the behavior of gastric inflammation in adolescents, which will help in the development of treatment strategies.

The aim of this study was to compare histological findings with dyspeptic symptoms in adolescents.

\section{Methods}

Epidemiological variables and data of upper gastrointestinal endoscopies were obtained from patients in routine clinical practice in a medical cen- ter in Crato, Ceará, Brazil, over a 6 month period (April 2005 to September 2005). The collected data were tabulated in an electronic database. The participating institution is a community-based hospital, serves as a primary care center for its region and had endoscopy unit of the open access, so that primary care providers can refer their patients directly without gastroenterological consultation. It is also a reference center for digestive disease. This prospective data base was not used to investigate consecutive adult patients complaining of dyspepsia, who were referred for endoscopy

All patients were adolescents aged 10 to 19 years. The pre-selection of patients was performed by general practitioners in primary health care, guiding individuals who had dyspeptic complaints and were considered fit for endoscopy. Dyspepsia was defined according to the Rome II Consensus criteria as "moderate-to-very-severe pain and discomfort centered in the upper abdomen lasting for at least 4 weeks". In the absence of alarm symptoms and chronic intake of nonsteroidal anti-inflammatory drugs (NSAIDs), it was defined as "uncomplicated." Dyspepsia subtypes were categorized as reflux-like, ulcer-like, dysmotility-like, or unspecified as previously described.

A questionnaire was systematically submitted to all patients prior to endoscopy after signing the informed consent. It included multiple variables such as: age, sex, comorbidities and coprescriptions (including steroids and anticoagulants), regular NSAIDs intake, $H$. pylori infection, presence of any alarm symptoms and type of dyspepsia. The endoscopist entered the procedure data, including presenting symptoms, preprocedure diagnosis, recent tests, and diagnostic findings immediately following endoscopy. Critical variables including age, sex, comorbidities, procedure indication, and endoscopic findings were required fields for all patients. Only patients who had dyspepsia as an indication were considered. Records of monitoring patients were excluded from the study. 
Patients were included if they had dyspeptic symptoms; complete diagnostic examination of the esophagus, stomach, and duodenum; no proven preprocedure upper Gl diagnosis; no previous varices treatment, dilation, stenting, tumor ablation, or foreign body removal; and no recent endoscopy or barium meal. $H$. pylori infection was detected by rapid urease test and histology using standard diagnostic techniques, the Silver and Giemsa stains. Gastritis was diagnosed in accordance with Sydney System modified by Dixon (8).

Analysis of variance was used for the comparison of mean values, and the chi-square test with Yates's correction, the Fisher's test and the odds ratio, when appropriate, were used for the comparison of proportions. The fifth percentile, i.e., the value of alpha error, was chosen as the cut-off point. A post-hoc analysis was performed for the calculation of statistical error. Linear correlation was performed by Pearson's correlation coefficient.

All components necessary for human research criteria were used and scrutinized by the local Ethics Committee.

\section{Results}

A total of 162 consecutive outpatients with dyspepsia as an indication for upper Gl endoscopy were inserted in the structured database. The mean age of the sample was 16 years old. There were 120 females (74\%) and 42 males (26\%). A total of 69 patients (42.59\%) were on NSAIDs in the past 30 days before endoscopy. Epigastric pain was the main clinical feature. There were 97 patients (59.87\%) with moderate to severe epigastric pain for a minimum of 90 days. Half of the patients had heartburn about 3 days a week. Regurgitation was present in 49 patients (30.8\%). The great majority had postprandial fullness. Half of patients had nausea. Almost none had vomiting. There were 9 patients with hematemesis and none with melena and/or hematochezia.
The main preprocedure diagnosis was gastritis in 135 patients (83\%).

\section{Endoscopic Findings}

Gastritis was present in 68 patients (41.9\%), esophagitis in 27 patients $(16,7 \%)$, peptic ulcer in 12 (6,8\%), 2 patients had gastric ulcers. Endoscopy was considered normal in 74 patients (45,7\%). One patient had hiatal hernia, another ectopic pancreas and another Brunner's tumor of duodenum. The rapid urease test was positive in $58,6 \%$ of patients.

\section{Histopathological Findings}

Histopathology examination was performed on biopsy specimens of all 162 patients undergoing endoscopic examination. H. pylori were present in 123 (75.9\%) of cases. Considering the rapid urease test and histopathology, the prevalence of $H$. pylori in the study sample was $78 \%$. The diagnosis of gastritis was present in $70.9 \%$ of biopsies. In all instances the gastritis was in antrum and in $75.6 \%$ of patients with histologic gastritis was also found in the body. Most individuals (58.2\%) had superficial gastritis, and $96.5 \%$ of gastritis had mild to moderate intensity. 19 subjects (11.7\%) had intestinal metaplasia, these 18 subjects were positive for $H$. pylori (95\%), and only $75 \%$ of those without intestinal metaplasia were also positive for $\mathrm{Hp}$. This difference is very close to significance ( $p=0.58$ ). 31\% had lymphoid follicular hyperplasia. Of these, $98.2 \%$ were carriers of $H$. pylori, against $67 \%$ who had no follicular lymphoid hyperplasia. Foveolar hyperplasia was found in $86 \%$ of biopsies and reactive atypia in $73.0 \%$. It is important to report that one subject had mild dysplasia.

\section{Other Findings}

The fecal parasitology test was submitted by 135 patients, and 45 patients (34\%) had at least one parasite. All of these patients had Ascaris lumbricoides; Giardia lamblia and Entamoeba sp. were prevalents. 


\section{Histopathological findings confronted with clinical elements}

The relationship between each digestive sign or symptom and presence of gastritis on histopathology were studied (Table 1-3). The association between epigastric pain and gastritis on histopathology was analyzed. Regarding location, the frequency of gastritis in the antrum and incisura angularis was significantly higher in subjects who had epigastric pain $(p=0,004)$; regarding the type, superficial gastritis was 2 times more frequent among subjects who had epigastric pain than those who do not presented $(p=0,012)$ with respect to intensity, gastritis with greater intensity $(p=0,016)$ was significantly more frequent among those who had epigastric pain. Regarding intestinal metaplasia $(p=0,743)$ and lymphoid follicular hyperplasia $(p=0,768)$ no correlation with epigastric pain (Table 1). There was

Table 1. Relation between "epigastric pain" and the presence of gastritis on the histopathological exam.

\begin{tabular}{|c|c|c|c|c|}
\hline \multirow{2}{*}{ Characteristics of gastritis } & \multirow{2}{*}{ Total } & \multicolumn{2}{|c|}{ "epigastric pain" } & \multirow{2}{*}{ p-value } \\
\hline & & Absent $(\mathrm{N}=27)\left(\%^{1}\right)$ & Present $(\mathrm{N}=1350)\left(\%^{2}\right)$ & \\
\hline \multicolumn{5}{|l|}{ Gastritis } \\
\hline Absent & 47 & 52,0 & 24,4 & \multirow{2}{*}{$0,004^{4}$} \\
\hline Present & 115 & 48,0 & 75,6 & \\
\hline \multicolumn{5}{|l|}{ Gastritis of the Antrum } \\
\hline Absent & 47 & 52,0 & 24,4 & \multirow{2}{*}{$0,004^{4}$} \\
\hline Present & 115 & 48,0 & 75,6 & \\
\hline \multicolumn{5}{|l|}{ Gastritis of the Body } \\
\hline Absent & 75 & 52,0 & 24,4 & \multirow{2}{*}{$0,291^{4}$} \\
\hline Present & 87 & 55,6 & 75,6 & \\
\hline \multicolumn{5}{|l|}{ Gastritis of the Incisura } \\
\hline Absent & 53 & 52,0 & 24,4 & \multirow{2}{*}{$0,006^{4}$} \\
\hline Present & 109 & 55,6 & 75,6 & \\
\hline \multicolumn{5}{|l|}{ Type of gastritis } \\
\hline Absence of Gastritis & 47 & 52,0 & 24,4 & \multirow{3}{*}{$0,012^{4}$} \\
\hline Superficial & 67 & 55,6 & 75,6 & \\
\hline Difuse & 48 & 51,9 & 75,6 & \\
\hline \multicolumn{5}{|l|}{ Intensity of Gastritis } \\
\hline Absence of Gastritis & 47 & 52,0 & 24,4 & \multirow{3}{*}{$0,016^{4}$} \\
\hline Mild & 51 & 55,6 & 75,6 & \\
\hline Moderate or severe & 64 & 51,9 & 75,6 & \\
\hline \multicolumn{5}{|l|}{ Metaplasia } \\
\hline Absent & 143 & 52,0 & 24,4 & \multirow{2}{*}{$0,743^{3}$} \\
\hline Present & 19 & 92,6 & 75,6 & \\
\hline \multicolumn{5}{|l|}{ Hiperplasia } \\
\hline Absent & 106 & 52,0 & 24,4 & \multirow{2}{*}{$0768^{4}$} \\
\hline Present & 56 & 63,0 & 75,6 & \\
\hline \multicolumn{4}{|c|}{$\begin{array}{l}\text { 1. Probability to have or no Gastritis, as it doesn't show } \\
\text { "epigastric pain". }\end{array}$} & \\
\hline 3. Fisher's exact test. & & 4. $X^{2}$ test & & \\
\hline
\end{tabular}


no association between heartburn and gastritis on histopathology (Table 2). Gastritis of the antrum and incisura angularis was present with a frequency significantly higher among those with regurgitation (Table 3). Gastritis in histopathology showed no association with gastric fullness and nausea (table 4 and 5), neither vomiting nor gastrointestinal bleeding (table 6 and 7). Of the 162 patients studied with clinical dyspepsia, 123 (75.9\%) had H. pylori infection; of which 115 (70.9\%) showed histology consistent with gastritis. We estimated the probability that the adolescent is infected with $H$. pylori, since had or no signs of digestive symptoms. The likelihood of having $\mathrm{H}$. pylori among those who had pain in the stomach was $81 \%$, while those who did not have symptom the probability was $63 \%$, and

Table 2. Relation between "heartburn" and the presence of gastritis on the histopathological exam. histopathological exam.

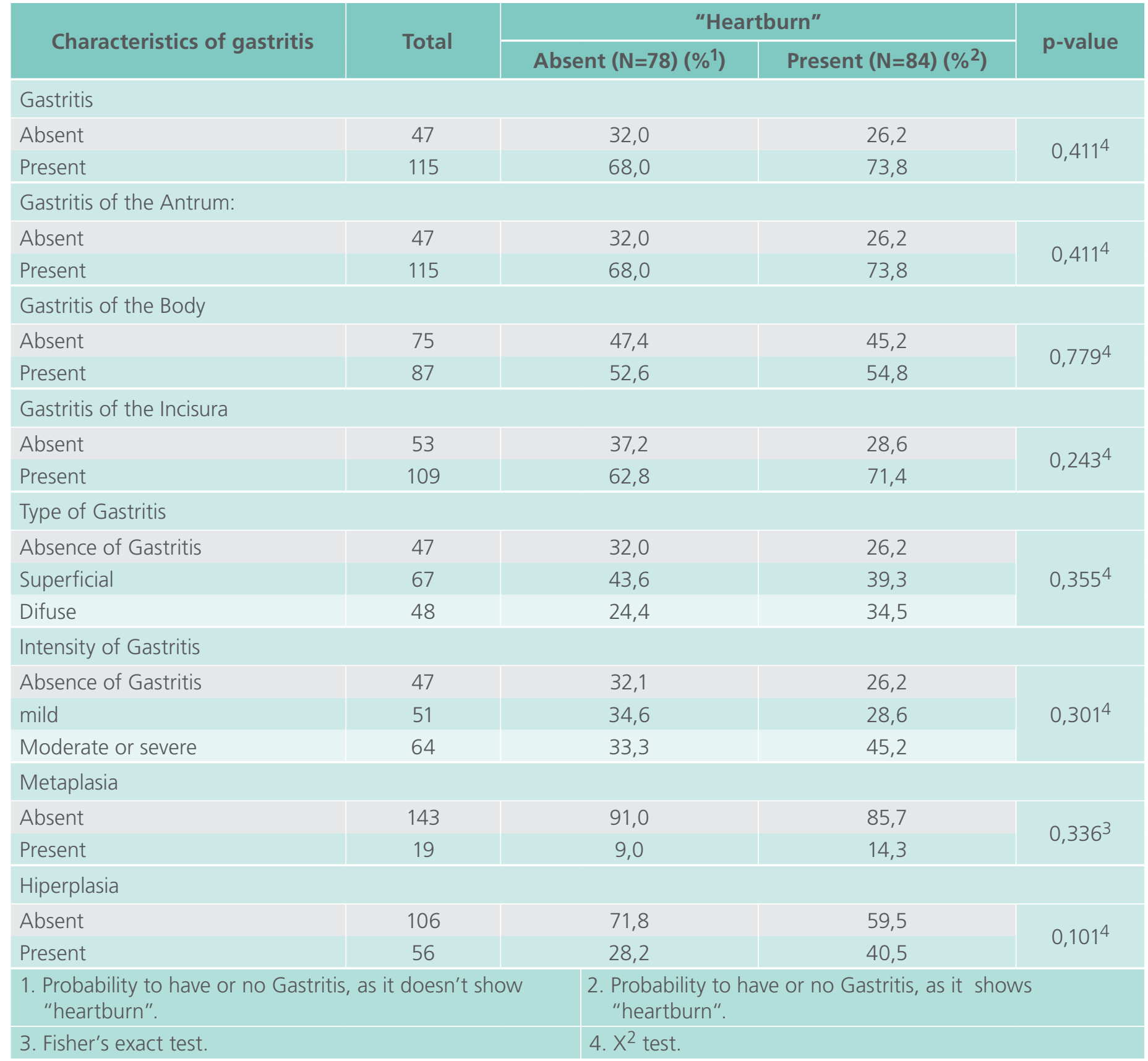


Table 3. Relation between "regurgitation" and the presence of gastritis on the histopathological exam.

\begin{tabular}{|c|c|c|c|c|}
\hline \multirow{2}{*}{ Characteristics of gastritis } & \multirow{2}{*}{ Total } & \multicolumn{2}{|c|}{ "Regurgitation" } & \multirow{2}{*}{$p$-value } \\
\hline & & Absent $(\mathrm{N}=112)\left(\%{ }^{1}\right)$ & Present $(\mathrm{N}=50)\left(\%^{2}\right)$ & \\
\hline \multicolumn{5}{|l|}{ Gastritis } \\
\hline Absent & 47 & 34,0 & 18,0 & \multirow{2}{*}{$0,039^{4}$} \\
\hline Present & 115 & 66,1 & 82,0 & \\
\hline \multicolumn{5}{|l|}{ Gastritis of the Antrum: } \\
\hline Absent & 47 & 34,0 & 18,0 & \multirow{2}{*}{$0,039^{4}$} \\
\hline Present & 115 & 66,1 & 82,0 & \\
\hline \multicolumn{5}{|l|}{ Gastritis of the Body } \\
\hline Absent & 75 & 50,0 & 38,0 & \multirow{2}{*}{$0,157^{4}$} \\
\hline Present & 87 & 50,0 & 62,0 & \\
\hline \multicolumn{5}{|l|}{ Gastritis of the Incisura } \\
\hline Absent & 53 & 37,2 & 22,0 & \multirow{2}{*}{$0,052^{4}$} \\
\hline Present & 109 & 62,8 & 78,0 & \\
\hline \multicolumn{5}{|l|}{ Type of Gastritis } \\
\hline Absence of Gastritis & 47 & 33,9 & 18,0 & \multirow{3}{*}{$0,111^{4}$} \\
\hline Superficial & 67 & 39,3 & 46,0 & \\
\hline Difuse & 48 & 26,8 & 36,0 & \\
\hline \multicolumn{5}{|l|}{ Intensity of Gastritis } \\
\hline Absence of Gastritis & 47 & 33,9 & 18,0 & \multirow{3}{*}{$0,119^{4}$} \\
\hline mild & 51 & 29,5 & 36,0 & \\
\hline Moderate or severe & 64 & 36,6 & 46,0 & \\
\hline \multicolumn{5}{|l|}{ Metaplasia } \\
\hline Absent & 143 & 87,5 & 90,0 & \multirow{2}{*}{$0,648^{3}$} \\
\hline Present & 19 & 12,5 & 10,0 & \\
\hline \multicolumn{5}{|l|}{ Hiperplasia } \\
\hline Absent & 106 & 68,8 & 58,0 & \multirow{2}{*}{$0,184^{4}$} \\
\hline Present & 56 & 31,3 & 42,0 & \\
\hline \multicolumn{4}{|c|}{$\begin{array}{l}\text { 1. Probability to have or no Gastritis, as it doesn't show } \\
\text { "regurgitation". }\end{array}$} & \\
\hline 3. Fisher's exact test. & & 4. $X^{2}$ test. & & \\
\hline
\end{tabular}


Table 4. Relation between "postprandial fullness" and the presence of gastritis on the histopathological exam.

\begin{tabular}{|c|c|c|c|c|}
\hline \multirow{2}{*}{ Characteristics of gastritis } & \multirow{2}{*}{ Total } & \multicolumn{2}{|c|}{ "fulness" } & \multirow{2}{*}{ p-value } \\
\hline & & Absent $(\mathrm{N}=57)\left(\%^{1}\right)$ & Present $(\mathrm{N}=105)\left(\%^{2}\right)$ & \\
\hline \multicolumn{5}{|l|}{ Gastritis } \\
\hline Absent & 47 & 35,1 & 25,7 & \multirow{2}{*}{$0,209^{4}$} \\
\hline Present & 115 & 64,9 & 74,3 & \\
\hline \multicolumn{5}{|l|}{ Gastritis of the Antrum: } \\
\hline Absent & 47 & 35,1 & 25,7 & \multirow{2}{*}{$0,209^{4}$} \\
\hline Present & 115 & 64,9 & 74,3 & \\
\hline \multicolumn{5}{|l|}{ Gastritis of the Body } \\
\hline Absent & 75 & 49,1 & 44,8 & \multirow{2}{*}{$0,595^{4}$} \\
\hline Present & 87 & 50,9 & 55,2 & \\
\hline \multicolumn{5}{|l|}{ Gastritis of the Incisura } \\
\hline Absent & 53 & 36,8 & 30,5 & \multirow{2}{*}{$0,410^{4}$} \\
\hline Present & 109 & 63,2 & 69,5 & \\
\hline \multicolumn{5}{|l|}{ Type of Gastritis } \\
\hline Absence of Gastritis & 47 & 35,1 & 25,7 & \multirow{3}{*}{$0,448^{4}$} \\
\hline Superficial & 67 & 38,6 & 42,9 & \\
\hline Difuse & 48 & 26,3 & 31,4 & \\
\hline \multicolumn{5}{|l|}{ Intensity of Gastritis } \\
\hline Absence of Gastritis & 47 & 35,1 & 25,7 & \multirow{3}{*}{$0,443^{4}$} \\
\hline mild & 51 & 29,8 & 32,4 & \\
\hline Moderate or severe & 64 & 35,1 & 41,9 & \\
\hline \multicolumn{5}{|l|}{ Metaplasia } \\
\hline Absent & 143 & 91,2 & 86,7 & \multirow{2}{*}{$0,389^{3}$} \\
\hline Present & 19 & 8,8 & 13,3 & \\
\hline \multicolumn{5}{|l|}{ Hiperplasia } \\
\hline Absent & 106 & 66,7 & 64,8 & \multirow{2}{*}{$0,808^{4}$} \\
\hline Present & 56 & 33,3 & 35,2 & \\
\hline \multicolumn{2}{|c|}{$\begin{array}{l}\text { 1. Probability to have or no Gastritis, as it doesn't shon } \\
\text { "postprandial fullness". }\end{array}$} & \multicolumn{3}{|c|}{$\begin{array}{l}\text { 2. Probability to have or no Gastritis, as it shows } \\
\text { "postprandial fullness". }\end{array}$} \\
\hline \multicolumn{2}{|c|}{ 3. Fisher's exact test. } & \multicolumn{3}{|c|}{ 4. $X^{2}$ test. } \\
\hline
\end{tabular}


Table 5. Relation between "nausea" and the presence of gastritis on the histopathological exam.

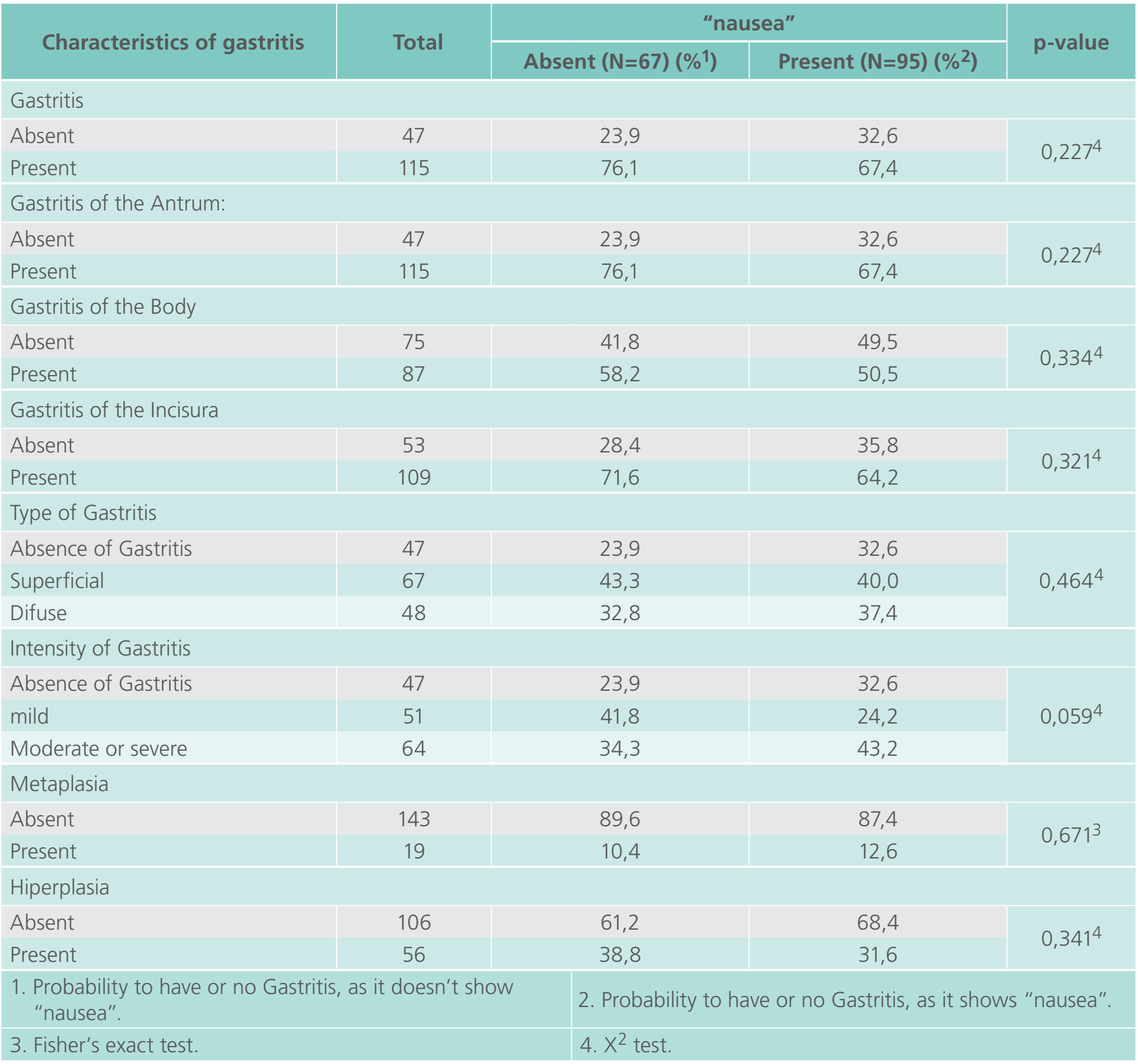


Table 6. Relation between "vomiting" and the presence of gastritis on the histopathological exam.

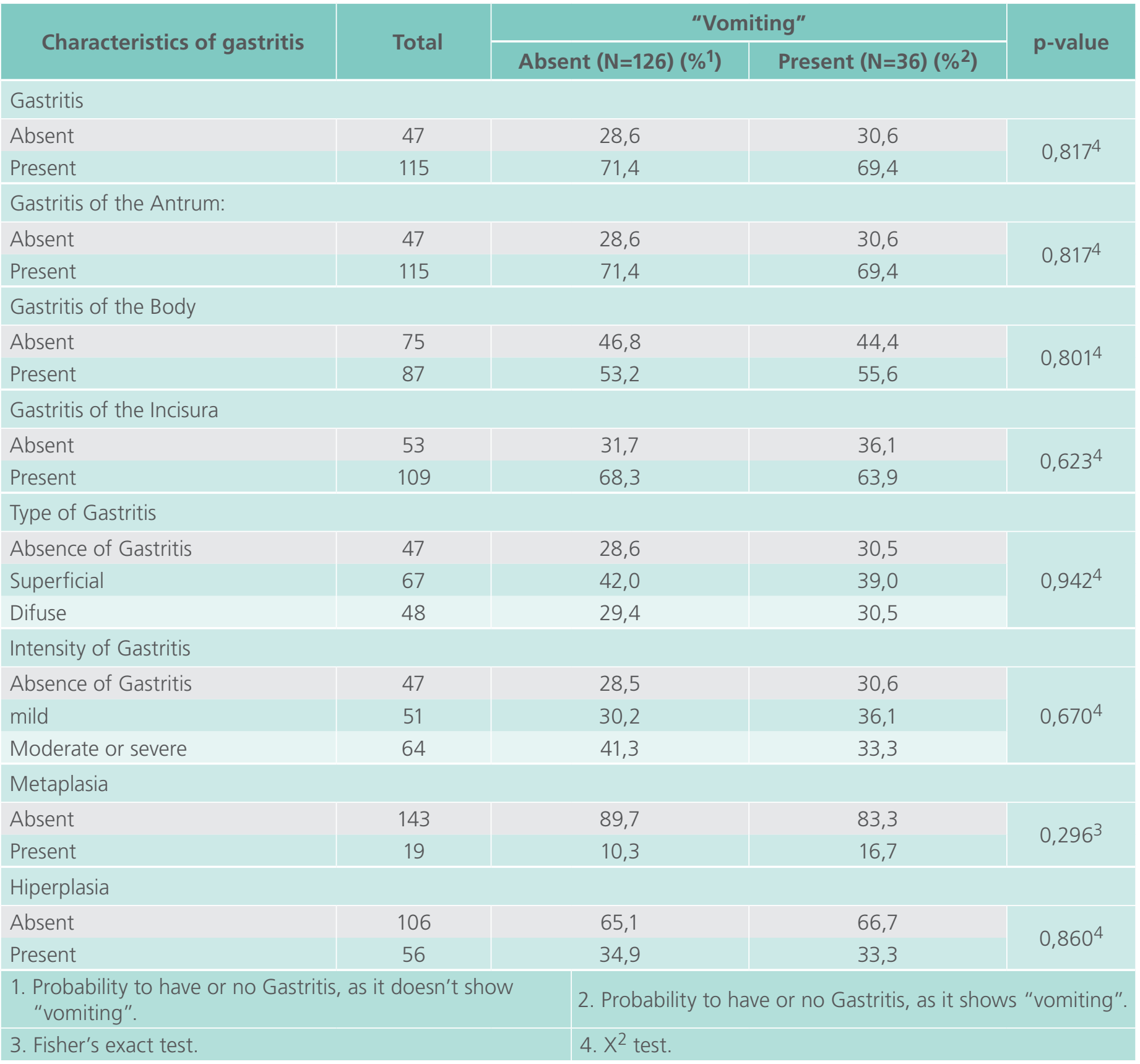


Table 7. Relation between "bleeding" and the presence of gastritis on the histopathological exam.

\begin{tabular}{|c|c|c|c|c|}
\hline \multirow{2}{*}{ Characteristics of gastritis } & \multirow{2}{*}{ Total } & \multicolumn{2}{|c|}{ "bleeding" } & \multirow{2}{*}{$p$-value } \\
\hline & & Absent $(\mathrm{N}=153)\left(\%{ }^{1}\right)$ & Present $(\mathrm{N}=9)\left(\%^{2}\right)$ & \\
\hline \multicolumn{5}{|l|}{ Gastritis } \\
\hline Absent & 47 & 29,4 & 22,2 & \multirow{2}{*}{$1,000^{4}$} \\
\hline Present & 115 & 70,6 & 77,8 & \\
\hline \multicolumn{5}{|l|}{ Gastritis of the Antrum: } \\
\hline Absent & 47 & 29,4 & 22,2 & \multirow{2}{*}{$1,000^{4}$} \\
\hline Present & 115 & 70,6 & 77,8 & \\
\hline \multicolumn{5}{|l|}{ Gastritis of the Body } \\
\hline Absent & 75 & 47,7 & 22,2 & \multirow{2}{*}{$0,178^{4}$} \\
\hline Present & 87 & 52,3 & 77,8 & \\
\hline \multicolumn{5}{|l|}{ Gastritis of the Incisura } \\
\hline Absent & 53 & 33,3 & 22,2 & \multirow{2}{*}{$0,719^{4}$} \\
\hline Present & 109 & 66,7 & 77,8 & \\
\hline \multicolumn{5}{|l|}{ Type of Gastritis } \\
\hline Absence of Gastritis & 47 & 29,4 & 22,2 & \multirow{3}{*}{$1,000^{4}$} \\
\hline Superficial & 67 & 41,2 & 44,4 & \\
\hline Difuse & 48 & 29,4 & 33,3 & \\
\hline \multicolumn{5}{|l|}{ Intensity of Gastritis } \\
\hline Absence of Gastritis & 47 & 29,4 & 22,2 & \multirow{3}{*}{$1,000^{4}$} \\
\hline mild & 51 & 31,4 & 33,3 & \\
\hline Moderate or severe & 64 & 39,2 & 44,4 & \\
\hline \multicolumn{5}{|l|}{ Metaplasia } \\
\hline Absent & 143 & 88,2 & 88,9 & \multirow{2}{*}{$1,000^{3}$} \\
\hline Present & 19 & 11,8 & 11,1 & \\
\hline \multicolumn{5}{|l|}{ Hiperplasia } \\
\hline Absent & 106 & 64,7 & 77,8 & \multirow{2}{*}{$0,720^{4}$} \\
\hline Present & 56 & 35,3 & 22,2 & \\
\hline \multicolumn{4}{|c|}{$\begin{array}{l}\text { 1. Probability to have or no Gastritis, as it doesn't show } \\
\text { "bleeding". }\end{array}$} & "bleeding". \\
\hline \multicolumn{2}{|l|}{ 3. Fisher's exact test. } & \multicolumn{3}{|l|}{ 4. $X^{2}$ test. } \\
\hline
\end{tabular}


his difference was significantly different $(p=0,043)$. For others signs or symptoms the odds not differ significantly.

\section{Discussion}

All 162 patients in the study underwent biopsy with histopathology. The diagnosis of gastritis was present in $70.9 \%$ of cases, these numbers are very close to the prevalence of $\mathrm{H}$. pylori, allowing formulate the theory that $H$. pylori is involved in the pathogenesis of gastric inflammation in the present study, corroborating data from literature [3]. The place of occurrence in all patients with gastritis was the gastric antrum and in $75.6 \%$ of cases also occurred in the body. This gastritis was mostly superficial and the type mild to moderate intensity. An important finding was the presence of intestinal metaplasia in 19 individuals (11.7\%) and almost all had H.pylori. An individual had mild dysplasia. These findings, similar to those described in the literature, supports the idea that in childhood is the trigger of events that will culminate with the appearance of intestinal type gastric adenocarcinoma [9-12]. Not forgetting that other factors such as heredity, diet (excessive salt consumption, poor diet in fresh fruits and vegetables) and smoking, contribute substantially to the development of gastric atrophy, and consequently an increased risk for stomach cancer. In the present study only $35 \%$ of subjects had follicular lymphoid hyperplasia, which contradicts the one found in the literature in which the follicular lymphoid hyperplasia is found in $100 \%$ of patients with Helicobacter pylori [13].

It has been reported that most children and adolescents with $H$. pylori infection manifested chronic active gastritis without predominance of anatomical site - antrum or body gastric [14]. Morphological changes accompanying $H$. pylori infection in dyspepsia is important in the follow-up and treatment of patients. Inflammation and intestinal metaplasia increase with increasing $\mathrm{Hp}$ intensity in dyspeptic patients [15]. The Helicobacter pylori infection result in neutrophil activation and chronic gastritis and it has a role in the development of intestinal metaplasia. The greater the intensity of Helicobacter pylori infection, the greater the degrees of neutrophil activation, chronic gastritis and intestinal metaplasia [16].

The prevalence of $H$. pylori infection is high among children with dyspepsia and is associated with moderate/severe degrees of gastric inflammation [17]. Dyspeptic symptoms are frequent in children and its association with $H$. pylori infection is more evident than with recurrent abdominal pain [18]. This study revealed a probability of $81 \%$ of patients with $H$. pylori infection presenting epigastric pain. This relationship was statistically significant allowing the question: Would the $H$. pylori infection associated with functional dyspepsia? Several studies with adults have found no relationship of $\mathrm{Hp}$ with functional dyspepsia [19-24]. Also Kalach et al. [25] in a study of children observed no relationship of functional dyspepsia with $H$. pylori. Unlike, Shmuely et al. [26], found a quite evidence of this association. It is notable that $H$. pylori eradication therapy has a small but statistically significant effect in $H$. pylori positive non-ulcer dyspepsia [27-31]. When H. pylori infection is studied in children and adolescents there is a strong correlation with gastrointestinal symptoms $[18,32,33]$.

Rivera et al [34], analyzed 264 children and adolescents from three months to 17 years old with dyspeptic complaints all from Costa Rica, determining the prevalence of $H$. pylori by culture and histopathology of the gastric mucosa. Ninety-six $(36.3 \%)$ of the children had some degree of gastritis, and in 73 (76\%) of them were identified $\mathrm{Hp}$. Concluded that these data confirm the importance of investigating Helicobacter pylori in children and adolescents with gastric discomfort, especially in developing countries.

Bala and Czerwionka-Szaflarska [35], investigating chronic abdominal pain, in Poland, selected 
910 children and adolescents with chronic gastritis and Helicobacter pylori positive. Concluded that chronic gastritis associated with Helicobacter pylori in children and adolescents with chronic abdominal pain, occurred in $25 \%$ of patients, i.e. a quarter of the population studied. The authors suggested that abdominal pain should be considered during diagnostic investigation as relevant clinical data.

Unlike, Turkan et al. [36] concluded that there may be an inverse relation between severity of symptoms and level of $H$. pylori induced gastric inflammation in patients with functional dyspepsia, despite the small numbers of the study population.

This study also noted a correlation between the presence of epigastric pain and gastritis of the antrum and incisura angularis with extension of this correlation to the type of superficial gastritis of moderate intensity, especially when related to H. pylori infection. Patients with intestinal metaplasia and lymphoid follicular hyperplasia showed no correlation with symptoms, demonstrating that cellular changes in gastric mucosa have no clinical significance. Mysorekar et al. [37], verifying histopathological changes of antral mucosa in 355 adult patients in India, found a prevalence of $61.4 \%$ for $\mathrm{Hp}$, with an association of this pathogen with antral severe chronic active gastritis, presence of lymphoid follicles, intestinal metaplasia and dysplasia.

A considerable number of studies reported that eradication of the $\mathrm{Hp}$ halts the progression of preneoplastic lesions. Gastric atrophy in the corpus could regress after eradicating $H$. pylori; however, this result was not seen for gastric atrophy of the antrum or for IM of the corpus and antrum. The development of IM in the stomach is not reversible by H. pylori eradication and possibly represents a point of no return [38-43]. There is consistent evidence that incidence of chronic atrophic gastritis is very low in the absence of $H$. pylori infection [44]. This study was not detected chronic atrophic gastritis, which suggests that the presence of these lesions occurs at an older age. Moreover, it is possible that H. pylori eradication at this stage, an initial step of life, delaying the appearance of premalignant lesions.

Some limitations of this study should be mentioned. First, the number of individuals included could affect the quality of the analysis ( $n=162$ ). Second, the absence of asymptomatic individuals as a control could affect the results. Although, the control considered has been individuals of the sampled without gastritis.

In conclusion, this study showed a very consistent correlation between epigastric pain and moderate to severe superficial gastritis, most often associated with $\mathrm{Hp}$ infection. In contrast, no correlation between epigastric pain and intestinal metaplasia was observed, the same having been an occasional histopathological finding. On the other hand, gastritis of the antrum and angular notch revealed a statistically significant correlation with regurgitation. Gastritis in histopathology was not associated with postprandial fullness, nausea, vomiting or gastrointestinal bleeding. Other evidence from randomized studies, with extended sample will be needed to confirm the findings 


\section{References}

1. Lauwers GY. Gastritis: Beyond Helicobacter pylori. Int J Surg Pathol, 2010; Supplement to 18(3) 28S-32S.

2. Sepulveda AR, Patil M. Practical Approach to the Pathologic Diagnosis of Gastritis. Arch Pathol Lab Med, 2008; 132: sp.

3. Yakoob MY, Hussainy AS. Chronic Gastritis and Helicobacter pylori: A Histopathological Study of Gastric Mucosae Biopsies. Journal of the College of Physicians and Surgeons Pakistan, 2010; 20 (11): 773-775.

4. Elseweidy MM, Taha MM, Younis NN, Ibrahim KS, Hamouda HA, Eldosouky MA, Soliman H. Gastritis Induced by Helicobacter pylori Infection in Experimental Rats. Dig Dis Sci, 2010; 55: 2770-2777.

5. Dîrnu R, Secureanu FA, Neamtu C,Totolici BD, Pop OT, Mitrut P, Mălăescu DG, Mogoantă L. Chronic gastritis with intestinal metaplasia: clinic-statistical, histological and immunohistochemical study. Rom J Morphol Embryol, 2012; 53(2): 293-297.

6. Redéen S, Petersson F, Kechagias S, Mardh E, Borch K. Natural history of chronic gastritis in a population-based cohort. Scand J Gastroenterol, 2010; 45: 540-549.

7. Tan VPY, Wong BCY. Helicobacter pylori and gastritis: Untangling a complex relationship 27 years on. J Gastroen Hepatol, 2011; 26 (Suppl. 1): 42-45.

8. Dixon MF, Genta RM, Yardley JH, Correa P. Classification and grading of gastritis. The updated Sydney System. Am. J. Surg. Pathol, 1996; 20(10): 1161-1181.

9. IARC - Working group. IARC working group on the evaluation of carcinogenic risks to humans: some industrial chemicals Lyon, 15-22 February 1994. IARC. Monogr Eval Carcinog Risks Hum. 1994;60:1-560.

10. Ekström AM, Held M, Hansson LE, Engstand L, Nyrén O. Helicobacter pylori in gastric cancer established by CagA immunoblot as a marker of past infection. Gastroenterology. 2001; 12:784-91.

11. Bornschein J, Selgrad M, Warnecke M, Kuester D, Wex T, Malertheiner P. H. pylori infection is a key risk factor for proximal gastric cancer. Dig Dis Sci.2010; 55: 3124-31.

12. Correa, P. A Human Model of Gastric Carcinogenesis.Cancer Res, 1988; 48: 3554-3560.

13. Genta RM, Wentzell LM, Hamner J. Linphoid follicles in Helicobacter pylori infection: frequency, distribution and response to triple therapy. Hum. Pathol, 1993; 24: 577-583.

14. Langner M, Machado RS, Patricio FRS, Kawakami E. Evaluation of gastric histology in children and adolescents with Helicobacter pylori gastritis using the update Sydney System. Arq Gastroenterol, 2009; 46(4): 328-33.

15. Turkay C, Erbayrak M, Bavbek N, Yendunya S, Eraslane, Kasapolu B. Helicobacter pylori and histopathological findings in patients with dyspepsia. Turk J Gastroenterol, 2011; 22 (2): 122-127.
16. Tanko MN, Manasseh AN, Echejoh GO, Mandong BM, Malu AO, Okeke EM; Ladep N, Agaba El. Relation between Helicobacter pylori, inflammatory (neutrophil) activity, chronic gastritis, gastric atrophy and intestinal metaplasia. Nigerian Journal of Clinical Practice, 2008; II(3): 270-274.

17. Tinelli C, Zagari M, Bazzoli F. Upper gastrointestinal histopathological findings in children and adolescents with nonulcer dyspepsia with Helicobacter pylori infection. J Pediatr Gastroenterol Nutr, 2012; 55 (5): 523-9.

18. De Giacomo C, Valdambrini V, Lizzoli F, Gissi A, Palestra M. A Population-Based Survey on Gastrointestinal Tract Symptoms and Helicobacter pylori Infection in Children and Adolescents. Helicobacter, 2002; 7(6): 356-63.

19. Perri F, Festa V, Grossi E, Garbagna N, Leandro G, Andriulli A. Dyspepsia and Helicobacter pylori infection: a prospective multicentre observational study. Dig Liver Dis, 2003; 35(3): 157164.

20. Lopez Gaston A, Andrusch A, Catuogno P. Functional Dyspepsia and infection by Helicobacter pylori: a causal relation does not exist. Acta Gastroenterol Latinoam, 2003; 33: 13-21.

21. Sarnelli G, Cuomo R, Janssens J, Tack J. Symptom patterns and pathophysiological mechanisms in dyspeptic patients with and without Helicobacter pylori. Dig Dis Sci, 2003; 48(12): 22292236.

22. Bode G, Brenner H, Adler G, Rothenbacher D. Helicobacter pylori infection, intake of analgesics or anti-inflammatory medication, and personal factors in relation to dyspeptic symptoms in patients of a general practitioner. Br J Gen Pract, 2000; 50(457): 615-6199.

23. Reshetnikov OV, Kurilovich SA, Tereshonok IN, Denisova DV, Zav'ialova LG, Krivenchuk NA, Zimina liu, Granberg C, Häivä VM. Dyspepsia and gastroesophageal reflux in adolescents. Ter Ark, 2002; 74 (2): 9-13.

24. Marzio L, Cappello G, Ballone E. Evaluation of dyspeptic symptoms in patients with and without Helicobacter pylori infection and normal upper gastrointestinal endoscopy. Dig Liver Dis, 2003; 35(3): 138-142.

25. Kalach N, Mention K, Guimber D, Michaud L, Spyckerelle C, Gottrand F. Helicobacter pylori infection is not associated with specific symptoms in nonulcer-dyspeptic children. Pediatrics, 2005. 115: 17-21.

26. Shmuely H, Obure S, Passaro DJ, Abuksis G, Yahav J, Fraser G, Pitlik S, Niv Y. Dyspepsia symptoms and Helicobacter pylori infection, Nakuru, Kenya. Emerg Infect Dis 2003; 9(9): 11031107.

27. Zhao B, Zhao J, Cheng WF, Shi WJ, Liu W, Pan XL, Zhang GX. Efficacy of Helicobacter pylori Eradication Therapy on Functional Dyspepsia: A Meta-Analysis of Randomized Controlled Studies With 12-Month Follow-up. J. Clin. Gastroenterol, 2014; 48(3): 241-7. 
28. Moayyedi P, Soo S, Deeks J, Forman D, Mason J, Innes M. Systematic review and economic evaluation of Helicobacter pylori eradication treatment for non $\neg$ ulcer dyspepsia. BMJ, 2000; 321: 659-64

29. Moayyedi P, Deeks J, Talley NJ, Delaney B, Forman D. An Update of the Cochrane Systematic Review of Helicobacter pylori Eradication Therapy in Nonulcer Dyspepsia: Resolving the Discrepancy between Systematic Reviews. Am J Gastroenterol, 2003; 98: 2621-2626.

30. Delaney B, Ford AC, Forman D, Moayyedi P, Qume M. WITHDRAWN: Initial management strategies for dyspepsia. Cochrane Database Syst Rev, 2009 7(4): CD001961.

31. Moayyedi P, Soo S, Deeks JJ, Delaney B, Harris A, Innes M, Oakes R, Wilson S, Roalfe A, Bennett C, Forman D. WITHDRAWN: Eradication of Helicobacter pylori for non-ulcer dyspepsia. Cochrane Database Syst Rev, 2011; 16(2): CD002096.

32. Dupont C, Benhamou PH, Kalach N, Raymond J. Helicobacter pylori infection in children. Rev Prat, 2000, 50(13): 1437-1441.

33. Sedlackova $M$, Malaty $H$, Volf $V$, Frühauf $P$, Marx $D$, Soucek A, Graham DY. Helicobacter pylori infection in a group of symptomatic and asymptomatic children and adolescents in the Czech Republic. Cas Lek Cesk, 2005; 142(2): 102-105.

34. Rivera P, Carranza A, Hernandez-Chavarria F. Helicobacter pylori in children in Hospital Nacional de Ninos, San Jose de Costa Rica. Acta Gastroenterol Latinoam, 2003; 33(3): 159-163.

35. Bala G, Czerwionka-Szaflarska M. Long term analysis of chronic gastritis with Helicobacter pylori infection in children and teenagers with chronic abdominal pain. Med Wieku Rozwoj, 2004; 8: 86-96

36. Turkkan E, Uslan I, Acartuk G, Topak N, Kahraman A, Dilek FM, Akcan Y, Karaman O, Colbay M, Yuksel S. Does Helicobacter pylori-induced infl ammation of gastric mucosa determine the severity of symptoms in functional dyspepsia? J Gastroenterol, 2009; 44: 66-70.

37. Mysorekar VV, Chitralekha, Dandekar P, Prakash BS. Antral histopathological changes in acid peptic disease associated with Helicobacter pylori. Indian J Pathol Microbiol, 1999; v.42, n.4, p.427-434

38. Wang J, Xu L, Shi R, Huang X, Li SWH, Huang Z, Zhang G. Gastric Atrophy and Intestinal Metaplasia before and after Helicobacter pylori Eradication: A Meta-Analysis. Digestion, 2011; 83: 253260.

39. Malfertheiner P. Gastric Atrophy Reversible or Irreversible after Helicobacter pylori eradication - An Open Question. Digestion, 2011; 83: 250-252.

40. Fang JY, Liu WZ, Shi Y, Ge ZZ, Xiao SD. Consensus on chronic gastritis in China - Second National Consensus Meeting on Chronic Gastritis (14-16 September 2006 Shanghai, China). J Dig Dis, 2007; 8; 107-119.
41. Egan BJ, Holmes K, O'Connor JH, O'Morain CA. Helicobacter pylori Gastritis, the Unifying Concept for Gastric Diseases. Helicobacter, 2010; 12 (Suppl. 2): 39-44.

42. Sipponen P. Chronic Gastritis in Former Times and Now. Helicobacter, 2010; 12 (Suppl. 2): 16-21.

43. Telaranta-Keerie A, Kara R, Paloheimo L, Harkonen M, Sipponen P. Prevalence of undiagnosed advanced atrophic corpus gastritis in Finland: an observational study among 4,256 volunteers without specific complaints. Scand J Gastroenterol, 2010; 45: 1036-1041

44. Adamu MAA, Weck MN, Gao L, Brenner H. Incidence of chronic atrophic gastritis: systematic review and meta-analysis of followup studies Eur J Epidemiol, (2010) 25: 439-448.

\section{Comment on this article:}

\section{(f) [in is $\mathbf{S}$ ?}

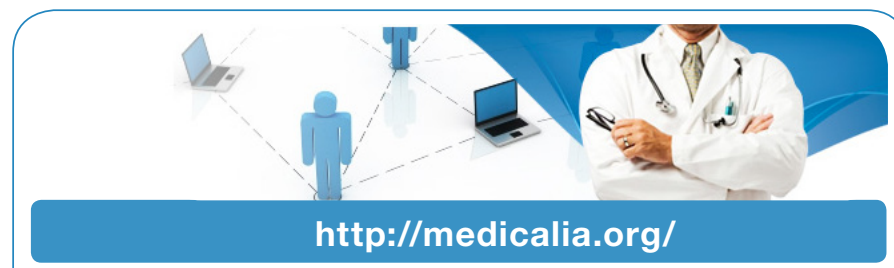

Where Doctors exchange clinical experiences, review their cases and share clinical knowledge. You can also access lots of medical publications for free. Join Now!

\section{Publish with iMedPub}

http://www.imed.pub

International Archives of Medicine is an open access journal publishing articles encompassing all aspects of medical science and clinical practice. IAM is considered a megajournal with independent sections on all areas of medicine. IAM is a really international journal with authors and board members from all around the world. The journal is widely indexed and classified Q1 in category Medicine. 